\title{
Quantum-chemical substantiation of collecting properties of acetylene reagents in flotation of sulphide minerals
} T. I. Yushina, Candidate of Engineering Sciences, Associate Professor, Head of the Department of Minerals Processing
and Technogenic Raw Materials ${ }^{1}$, e-mail: yuti62@mail.ru

S. A. Shchelkunov, Candidate of Chemical Sciences, Technical Director ${ }^{2}$, e-mail: shelkunov66@mail.ru

O. A. Malyshev, Candidate of Engineering Sciences, CEO², e-mail: omalyshev57@mail.ru

${ }^{1}$ NUST MISiS College of Mining, Moscow, Russia.

${ }^{2}$ BioKhimProm LLC, Moscow, Russia.

\begin{abstract}
The paper presents the analysis results of known data and performed adsorption and spectral IR studies of MIG-4E, DMIPEK and DC-80 acetylene reagents in interaction with galena $(\mathrm{PbS})$ and molybdenite $\left(\mathrm{Mo}_{2} \mathrm{~S}\right)$ sulphide minerals. The IR spectra analysis of pure reagents and products of their interaction with the surface of sulphide minerals has showed that the adsorption of MIG-4E molecules takes place on the surface of lead sulphides, and DMIPEC molecules are adsorbed on the surface of molybdenite. Quantum-chemical calculations of the total potential energy of the complexes have shown that the complex formed by a molecule of MIG-4E - PbS of (HUMO) complexes by nucleophilic mechanism has $2514.0873 \mathrm{kcal} / \mathrm{mol}$, which is almost an order of magnitude greater than the total potential energy $(270.0439 \mathrm{kcal} / \mathrm{mol}$ ) of MIG-4E - PbS (HUMO) complex formed by electrophilic mechanism.

Analysis of the calculated data of the total potential energy of complexes formed by MIG-4E reagent molecules with $\mathrm{PbS}$ surface and DMIPEC molecules with Mo2S surface has showed that the total energy of $\pi$-complexes formed by reagents by electrophilic mechanism differs by $47.7 \%$ among reagent molecules and amounts to $270.0439 \mathrm{kcal} / \mathrm{mol}$ for (MIG-4E + PbS) complex, and $141.9386 \mathrm{kcal} / \mathrm{mol}$ for $\left(\mathrm{DMIPEC}+\mathrm{Mo}_{2} \mathrm{~S}\right.$ ) complex in the (HUMO) state. Such a difference in the values of total energies of the complexes can correlate with the conformational ability of DMIPEC reagent molecules.

Usage of acetylene alcohols as additional selective collectors during flotation of a number of non-ferrous and precious metal ores has shown a significant increase in the extraction of target metals, which makes it possible to consider the reagents based on acetylene derivatives as promising for industrial applications.
\end{abstract}

Key words: flotation, adsorption, sulphide minerals, additional extraction, collecting properties, acetylene reagents, infrared spectroscopy, quantum-chemical investigations, nucleophilic and electrophilic mechanisms, electronic formula of $\pi$-complex.

DOI: $10.17580 / \mathrm{nfm} .2021 .02 .03$

\section{Introduction}

T The development of innovative technologies for the complex processing of mineral raw materials by flotation method is impossible without the progress in theoretical foundations of flotation and modern ideas about the action mechanisms of various flotation reagents with minerals. One of the most important acts of the flotation process is an interaction of a collector with the floated mineral surface [1]. Widely known chemical theory of A. F. Taggart [2], a chemisorption hypothesis of D. A. Shvedov [3-5] and other hypotheses of various researchers have not taken into account the requirements of modern flotation theory for the floated mineral surface state and have not been confirmed by the results of experimental studies [6-10].

It was shown in [10] that metal xanthate in molecular form can have the effect of removing liquid from the layer separating the mineral particle and gas bubble. Mineral extraction increases in the presence of metal dixanthogenide or xanthates in the sorption layer. It should be noted that metal dixanthogenide or xanthate precipitates are fixed only on the surface hydrophobized by a chemically fixed reagent. As [11] indicates, the pulp contains a large number of xanthate derivatives: xanthate ion, monothiocarbonate ion, xanthogenic acid, dixanthogenide, carbon disulphide. According to [12], it remains unclear which product is responsible for hydrophobization of a mineral despite a large number of investigations on the interaction of sulphide minerals with xanthates. The mineral surface hydrophobization, which proceeds only by one adsorption mechanism, is considered insufficient.

One of the means of purposeful increasing the collectors' sorption and creating an optimal ratio of its chemically fixed and physically sorbed form on the surface of floated minerals is a combination of the main sulfhydric collector (xanthate) and additional collectors - nonionized heteropolar compounds, as which a large number of different flotation reagents (thionocarbamates, S-ethers of dithiophosphoric acids, trithiocarbonates, thioacylanilides, etc.) are proposed and used [13-17]. Nonionized heteropolar compounds that do not contain a sulfur atom in their composition are also used in the mixtures of collectors. Selective action of such reagents is determined by the nature of their solidophilic fragments and sorption centers of the mineral [16, 18-19]. 
Acetylene compounds, represented by alcohols of various structures, are among such reagents [20-21]. They are characterized by collecting properties of acetylene derivatives, which differ in the formation mechanism from sulfhydric collectors arising on interaction with the surface of sulphide ore minerals in the course of flotation. In accordance with the Pearson principle (of hard and soft Lewis acids and bases), multiple $\mathrm{C} \equiv \mathrm{C}$ and $\mathrm{C}=\mathrm{C}$ bonds are assigned to the soft Lewis bases, hence they should demonstrate the greatest affinity with cations belonging to the class of soft acids, while the triple $\mathrm{C} \equiv \mathrm{C}$ bond is a softer base than the double $\mathrm{C}=\mathrm{C}$ bond in the molecule structure [22-23]. At the same time, the acetylene reagent adsorption by the example of MIG-4E proceeds more efficiently in quantitative aspect by a triple $\mathrm{C} \equiv \mathrm{C}$ bond [19].<smiles>C=C(C)C#CC(C)(C)O</smiles><smiles>C#CC=COCCCC</smiles><smiles>C#CC(C)(C)O</smiles>

Fig. 1. Molecule structure of reagents acetylene derivatives: $a$ - DMIPEC; $b-$ MIG-4E; $c-$ DC-80
This paper presents the results of the studies aimed at identifying cause-and-effect relations between the properties of acetylene reagents and indicators of additional extraction of various sulphide minerals into the foam product.

\section{The reagents under consideration}

Dimethyl(isopropenylethinyl)carbinol (DMIPEC), ethynylvinylbutyl ether (MIG-4E) and dimethyl(ethynyl) carbinol (DC-80) reagents have been selected from the group of acetylene hydrocarbons for research. The DMIPEC reagent (Fig. 1, a) is a tertiary acetylene alcohol having conjugated double and triple bonds in the molecule structure and possessing limited aqueous solubility of $\sim 2 \%$; MIG-4E (Fig. 1, b) is a water-insoluble acetylene ether and DC-80 (Fig. 1, c) is a terminal tertiary acetylene alcohol with unlimited aqueous solubility.

\section{Results and discussion \\ Study of flotation properties of acetylene alcohols}

The study of the DMIPEC acetylene reagent collecting properties has been carried out on copper, copperzinc and gold-bearing ores. Table 1 gives the results of flotation of Zhezkent deposit sulphide ores with a copper content of 5.2\% using DMIPEC reagent instead of MIBC (methyl isobutyl carbinol) base foaming agent.

Table 1

Results of flotation of Zhezkent deposit sulphide ores using DMIPEC reagent

\begin{tabular}{|c|c|c|c|c|c|c|c|c|c|}
\hline \multirow{2}{*}{$\begin{array}{l}\text { Sample } \\
\text { number }\end{array}$} & \multirow{2}{*}{ Product name } & \multirow{2}{*}{$\begin{array}{c}\text { Yield, } \\
\%\end{array}$} & \multicolumn{3}{|c|}{ Content, \% } & \multicolumn{3}{|c|}{ Recovery, \% } & \multirow{2}{*}{ Flotation conditions } \\
\hline & & & $\mathrm{Cu}$ & $\mathrm{Zn}$ & $\mathrm{Fe}$ & $\mathrm{Cu}$ & $\mathrm{Zn}$ & $\mathrm{Fe}$ & \\
\hline В 125 & Cu head & 6.1 & 25.65 & 1.60 & 28.47 & 30.13 & 4.02 & 7.01 & \multirow{5}{*}{$\begin{array}{l}\text { MIBC } 5+2 \mathrm{~g} / \mathrm{t} \\
1 \% \text { sol. } \\
E_{\mathrm{Cu}}-E_{\mathrm{Zn}}=26.11 \% \\
E_{\mathrm{Cu}}-E_{\mathrm{Zn}}=26.11 \% \\
\text { Fresh water. }\end{array}$} \\
\hline B 126 & $\mathrm{Cu}-\mathrm{Zn}$ concentrate & 11.6 & 21.81 & 7.44 & 27.33 & 48.71 & 35.57 & 12.79 & \\
\hline B 127 & $\mathrm{Cu}-\mathrm{Zn}$ middlings & 5.3 & 10.42 & 15.31 & 25.20 & 10.63 & 33.44 & 5.39 & \\
\hline \multirow[t]{2}{*}{ B 128} & Tailings Dump & 77.0 & 0.71 & 0.85 & 24.09 & 10.63 & 26.97 & 74.81 & \\
\hline & Ore & 100 & 5.19 & 2.43 & 24.79 & 100 & 100 & 100 & \\
\hline B 141 & Cu head & 12.0 & 23.56 & 2.31 & 28.50 & 53.75 & 10.96 & 13.85 & \multirow{5}{*}{$\begin{array}{l}\text { DMIPEC } 5+2 \mathrm{~g} / \mathrm{t} \\
E_{\mathrm{Cu}}-E_{\mathrm{Zn}}=42.79 \% \\
E_{\mathrm{Cu}}-E_{\mathrm{Zn}}=136.09 \% \\
\text { Fresh water. }\end{array}$} \\
\hline B 142 & $\mathrm{Cu}-\mathrm{Zn}$ concentrate & 13.2 & 14.74 & 13.24 & 26.29 & 36.99 & 69.08 & 14.11 & \\
\hline B 143 & $\mathrm{Cu}-\mathrm{Zn}$ middlings & 4.2 & 5.54 & 7.99 & 29.61 & 4.42 & 13.26 & 5.04 & \\
\hline \multirow[t]{2}{*}{ B 144} & Tailings Dump & 70.6 & 0.36 & 0.24 & 23.44 & 4.84 & 6.7 & 67.00 & \\
\hline & Ore & 100 & 5.26 & 2.53 & 24.70 & 100 & 100 & 100 & \\
\hline B 129 & Cu head & 15.5 & 20.95 & 2.67 & 27.64 & 62.00 & 16.19 & 17.18 & \multirow{5}{*}{$\begin{array}{l}\text { DMIPEC } 10 \mathrm{~g} / \mathrm{t} \\
E_{\mathrm{Cu}}-E_{\mathrm{Zn}}=45.81 \% \\
E_{\mathrm{Cu}}-E_{\mathrm{Zn}}=134.93 \% \\
\text { Fresh water. }\end{array}$} \\
\hline B 130 & $\mathrm{Cu}-\mathrm{Zn}$ concentrate & 11.4 & 13.27 & 13.72 & 25.72 & 28.88 & 61.21 & 11.76 & \\
\hline B 131 & $\mathrm{Cu}-\mathrm{Zn}$ middlings & 3.6 & 5.54 & 8.32 & 27.74 & 3.81 & 11.72 & 4.00 & \\
\hline \multirow[t]{2}{*}{ B 132} & Tailings Dump & 69.5 & 0.40 & 0.40 & 24.06 & 5.31 & 10.88 & 67.06 & \\
\hline & Ore & 100 & 5.24 & 2.56 & 24.94 & 100 & 100 & 100 & \\
\hline B 133 & Cu head & 17.22 & 20.47 & 2.96 & 28.30 & 66.73 & 20.20 & 19.47 & \multirow{5}{*}{$\begin{array}{l}\text { DMIPEC } 15 \mathrm{~g} / \mathrm{t} \\
E_{\mathrm{Cu}}-E_{\mathrm{Ln}}=46.53 \% \\
E_{\mathrm{Cu}}-E_{\mathrm{Ln}}=136.18 \% \\
\text { Fresh water. }\end{array}$} \\
\hline B 134 & $\mathrm{Cu}-\mathrm{Zn}$ concentrate & 8.21 & 13.88 & 15.82 & 24.73 & 21.25 & 51.47 & 8.11 & \\
\hline B 135 & $\mathrm{Cu}-\mathrm{Zn}$ middlings & 4.00 & 6.63 & 11.34 & 28.16 & 5.02 & 17.98 & 4.50 & \\
\hline \multirow[t]{2}{*}{ B 136} & Tailings Dump & 70.57 & 0.50 & 0.37 & 24.09 & 6.68 & 10.35 & 67.92 & \\
\hline & Ore & 100 & 5.29 & 2.52 & 25.03 & 100 & 100 & 100 & \\
\hline B 137 & Cu head & 20.32 & 18.85 & 3.84 & 25.98 & 72.83 & 31.10 & 21.44 & \multirow{5}{*}{$\begin{array}{l}\text { DMIPEC } 20 \mathrm{~g} / \mathrm{t} \\
E_{\mathrm{Cu}}-E_{\mathrm{Zn}}=41.73 \% \\
E_{\mathrm{Cu}}-E_{\mathrm{Zn}}=137.59 \% \\
\text { Fresh water. }\end{array}$} \\
\hline B 138 & $\mathrm{Cu}-\mathrm{Zn}$ concentrate & 10.51 & 10.37 & 13.95 & 26.50 & 20.72 & 58.01 & 11.32 & \\
\hline B 139 & $\mathrm{Cu}-\mathrm{Zn}$ middlings & 4.30 & 3.66 & 3.94 & 31.40 & 2.99 & 6.75 & 5.48 & \\
\hline \multirow[t]{2}{*}{ B 140} & Tailings Dump & 64.87 & 0.28 & 0.16 & 23.44 & 3.46 & 4.14 & 61.76 & \\
\hline & Ore & 100 & 5.26 & 2.50 & 24.62 & 100 & 100 & 100 & \\
\hline
\end{tabular}


The increase in extraction for copper alone was $7 \%$ at DMIPEC consumption of $20 \mathrm{~g} / \mathrm{t}$; the concentrate yield has increased by $12.13 \%$; the quality of concentrates has improved.

The DMIPEC reagent selective collecting properties in relation to sulphide minerals were revealed during flotation of copper-zinc ore of the Maleevskoye deposit (Eastern Kazakhstan) containing copper $3.15 \%$, zinc $3.87 \%$, iron $24.7 \%$. The research data are given in Table 2.

The results of research into flotation have showed that the copper content in the copper concentrate has increased from 21.43 to $26.33 \%$ with a simultaneous decrease in the iron mass fraction from 31.16 to $26.22 \%$. The selective nature of DMIPEC reagent is confirmed by simultaneous reduction of zinc losses with copper concentrate by $7.8 \%$.

The results of flotation of the gold-bearing ore of the Akbakai ore mining and processing enterprise containing $10.81 \mathrm{~g} / \mathrm{t}$ of gold using DMIPEC reagent given in Table 3 are of interest. The main collector is a butyl potassium xanthate (BPX), the foaming agent in the basic experiment is T-80. The increase in gold extraction was $9 \%$.

In addition, successful tests of collectors-frothers reagents based on acetylene alcohols have been carried out during flotation of some other types of sulphide ores, the results of which are published in [21, 24-28]. The results of practical studies have been supplemented with quantumchemical calculations performed for assessing the DMIPEC reagent selectivity, which confirmed the assumption about selective properties of acetylene reagents [27].

\section{Study of the interaction mechanism}

of acetylene reagents with sulphide minerals

Spectral analysis by infrared spectroscopy and the simplest quantum-chemical calculations have been carried out to substantiate the mechanism of interaction of acetylene reagents with sulphide minerals. The authors have used a computer simulation program for the reagents ChemBioDrav Ultra 14.0 and ChemBio3D Ultra 14.0 of a ChemOffice specialized complex developed by CambridgeSoft Corporation to calculate binding energy of complexes of acetylene reagents with metal cations of the crystal lattice of sulphide minerals.

The calculation of complexes formed by molecules of acetylene reagents with cations on the surface of sulphide minerals has been performed according to the MM2 program application - by the molecular mechanics technique, using ChemBio3D 11.0 package included into ChemBioOffice 2008 package (for Windows) developed by CambridgeSoft Corporation. The total potential energy (TPE) of a molecule can be represented as the following sum:

Table 2

Balance of closed flotation experiments on evaluating the DMIPEC reagent collecting ability on copper-zinc ore

\begin{tabular}{|c|c|c|c|c|c|c|c|c|c|c|}
\hline \multirow{2}{*}{ Product } & \multirow{2}{*}{$\begin{array}{c}\text { Yield, } \\
\%\end{array}$} & \multicolumn{4}{|c|}{ Content, \% } & \multicolumn{4}{|c|}{ Recovery, \% } & \multirow{2}{*}{$\begin{array}{c}\text { Selectivity } \\
\text { coefficient, \%, } E_{\mathrm{Cu}}-E_{\mathrm{Zn}}\end{array}$} \\
\hline & & $\mathrm{Pb}$ & $\mathrm{Zn}$ & $\mathrm{Cu}$ & $\mathrm{Fe}$ & $\mathrm{Pb}$ & $\mathrm{Zn}$ & $\mathrm{Cu}$ & $\mathrm{Fe}$ & \\
\hline \multicolumn{11}{|c|}{ Experiment No. 1. OPSB frothing agent (PA Khimprom LLC, Kemerovo) } \\
\hline Concentrate (Cu head) & 5.21 & 5.11 & 4.00 & 23.86 & 28.23 & 41.74 & 5.27 & 36.58 & 5.85 & \multirow{4}{*}{79.53} \\
\hline Concentrate (Cu cleaner) & 10.01 & 3.20 & 4.42 & 20.16 & 32.69 & 50.27 & 11.20 & 59.43 & 13.04 & \\
\hline Total Cu concentrate & 15.22 & 3.85 & 4.28 & 21.43 & 31.16 & 92.02 & 16.48 & 96.00 & 18.89 & \\
\hline Ore & 100.0 & 0.64 & 3.95 & 3.41 & 25.10 & 100.0 & 100.0 & 100.0 & 100.0 & \\
\hline \multicolumn{11}{|c|}{ Experiment No. 2. DMIPEC frothing agent } \\
\hline Concentrate (Cu head) & 3.40 & 6.76 & 2.55 & 23.41 & 25.74 & 37.33 & 2.25 & 25.31 & 3.55 & \multirow{5}{*}{87.40} \\
\hline Concentrate (Cu cleaner) & 8.09 & 4.45 & 3.07 & 27.56 & 26.42 & 58.36 & 6.42 & 70.76 & 8.65 & \\
\hline Total Cu concentrate & 11.49 & 5.13 & 2.92 & 26.33 & 26.22 & 95.69 & 8.66 & 96.07 & 12.20 & \\
\hline Cu scavenger flotation tailings & 88.51 & 0.03 & 3.99 & 0.14 & 24.50 & 4.31 & 91.34 & 3.93 & 87.80 & \\
\hline Ore & 100.0 & 0.62 & 3.87 & 3.15 & 24.70 & 100.0 & 100.0 & 100.0 & 100.0 & \\
\hline
\end{tabular}

Table 3

Results of gold-bearing ore flotation in the presence of DMIPEC acetylene foaming agent

\begin{tabular}{|c|c|c|c|c|c|c|}
\hline \multirow{2}{*}{ Products } & \multirow{2}{*}{$\begin{array}{l}\text { Yield, } \\
\%\end{array}$} & \multicolumn{2}{|c|}{ Content, g/t } & \multicolumn{2}{|c|}{ Recovery, \% } & \multirow{2}{*}{ Conditions of experiments } \\
\hline & & $\mathrm{Au}$ & $\mathrm{Ag}$ & $\mathrm{Au}$ & $\mathrm{Ag}$ & \\
\hline $\begin{array}{l}\text { Collective concentrate } \\
\text { Tailings } \\
\text { Ore }\end{array}$ & $\begin{array}{c}5.1 \\
94.9 \\
100.0\end{array}$ & $\begin{array}{l}174.5 \\
1.5 \\
10.81\end{array}$ & $\begin{array}{c}84.5 \\
3.3 \\
7.85\end{array}$ & $\begin{array}{c}82.3 \\
17.6 \\
100.0\end{array}$ & $\begin{array}{c}54.9 \\
45.1 \\
100.0\end{array}$ & $\begin{array}{l}\mathrm{BPX}-200 \mathrm{~g} / \mathrm{t} \\
\mathrm{T}-80-80 \mathrm{~g} / \mathrm{t} \\
\text { Flotation time }-5 \mathrm{~min}\end{array}$ \\
\hline $\begin{array}{l}\text { Collective concentrate } \\
\text { Tailings } \\
\text { Ore }\end{array}$ & $\begin{array}{c}5.0 \\
95.0 \\
100.0\end{array}$ & $\begin{array}{c}192.3 \\
1.6 \\
10.81\end{array}$ & $\begin{array}{l}88.75 \\
2.8 \\
7.85\end{array}$ & $\begin{array}{c}88.9 \\
12.1 \\
100.0\end{array}$ & $\begin{array}{l}56.52 \\
43.48 \\
100.0\end{array}$ & $\begin{array}{l}\mathrm{BPX}-200 \mathrm{~g} / \mathrm{t} \\
\text { DMIPEC }-33 \mathrm{~g} / \mathrm{t} \\
\text { Flotation time }-3 \mathrm{~min}\end{array}$ \\
\hline $\begin{array}{l}\text { Collective concentrate } \\
\text { Tailings } \\
\text { Ore }\end{array}$ & $\begin{array}{c}5.2 \\
94.8 \\
100.0\end{array}$ & $\begin{array}{c}193 \\
0.8 \\
10.81\end{array}$ & $\begin{array}{c}78.75 \\
3.9 \\
7.85\end{array}$ & $\begin{array}{c}92.94 \\
7.16 \\
100.0\end{array}$ & $\begin{array}{c}52.2 \\
47.8 \\
100.0\end{array}$ & $\begin{array}{l}\mathrm{BPX}-200 \mathrm{~g} / \mathrm{t} \\
\text { DMIPEC }-50 \mathrm{~g} / \mathrm{t} \\
\text { Flotation time }-3 \mathrm{~min}\end{array}$ \\
\hline
\end{tabular}




\section{Total energy $=$ Bond stretching energy + \\ + Bending energy + Torsion energy + \\ + Energy of the interaction of unbound atoms.}

The MM2 (Molecular mechanics) techniques is designed for modeling and calculating organic molecules. It takes into account the potential fields generated by all the atoms of the calculated system [27].

When assessing the effect of the excited (promoted) state on the valence state of carbon atoms, it should be taken into account that the carbon atom in the ground state has an electron configuration as $1 s^{2} 2 s^{2} 2 p_{x} 2 p_{y}$ and only two unpaired electrons; however, its stable derivatives are not of the $\mathrm{CX}_{2}$ type but of $\mathrm{CX}_{4}$, which means that its electronic configuration changes to $1 s^{2} 2 s^{2} 2 p_{x} 2 p_{y} 2 p_{z}$, and the energy increases by $\sim 97 \mathrm{kcal}$ higher than that of the $1 s^{2} 2 s^{2} 2 p_{x} 2 p_{y}$ electron configuration. Here, an increase in
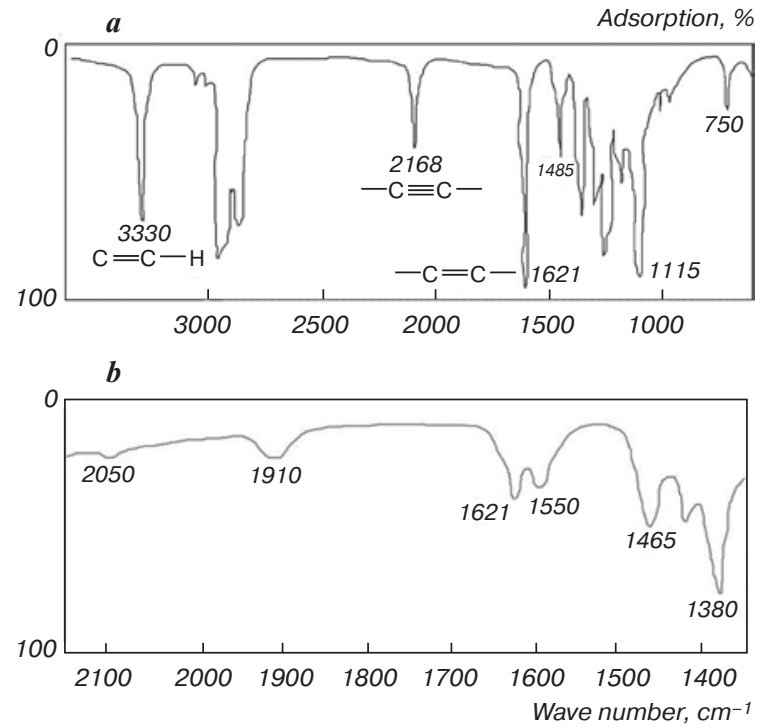

Fig. 2. IR absorption spectra of:

$a$ - MIG-4E reagent; $b$ - galena $(\mathrm{PbS})$ after adsorption of MIG-4E reagent on its surface (according to S. I. Ivankov [32])
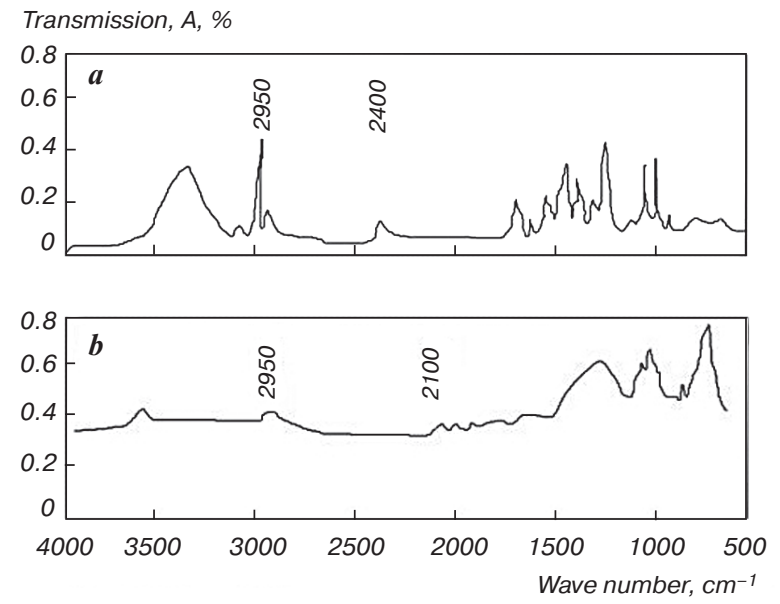

Fig. 3. IR spectra of:

$a-$ molecules of DMIPEC reagent; $b-$ molybdenite $\left(\mathrm{Mo}_{2} \mathrm{~S}\right)$ after adsorption of DMIPEC reagent on its surface the energy of carbon atoms is "sacrificed" to the stability of four resulting strong bonds of methane. The promotion energy of $\mathrm{CH}_{4}$ is $\sim 560 \mathrm{kcal}$, while it will be $\sim 275 \mathrm{kcal}$ for $\mathrm{CH}_{2}$. Thus, the reaction $\mathrm{C}(\mathrm{S})+\mathrm{H}_{2}(\mathrm{G})=\mathrm{CH}_{2}(\mathrm{G})$ is energetically less favorable than the reaction $\mathrm{C}(\mathrm{S})+2 \mathrm{H}_{2}(\mathrm{G})=$ $=\mathrm{CH}_{4}(\mathrm{G})$, despite the fact that more excitation energy is required to produce $\mathrm{CH}_{4}$ [29].

By the example given, it can be seen that the valence state is not a stationary state of the atom, which can be observed experimentally and calculated based on the available data.

Revealing the nature of the bonds formed during the adsorption interaction of galena $(\mathrm{PbS})$ minerals with molecules of MIG-4E reagent (Fig. 2, $\boldsymbol{a}, \boldsymbol{b}$ ) and molybdenite $\left(\mathrm{Mo}_{2} \mathrm{~S}\right)$ with molecules of DMIPEC reagent (Fig. $\left.3, \boldsymbol{a}, \boldsymbol{b}\right)$ has been carried out using IR spectroscopy. The data obtained during the interpretation of the results have been compared with the available reference data on IR absorption spectra for alkynes [30-31].

Valence oscillations in MIG-4E reagent for $\mathrm{C} \equiv \mathrm{C}$ bond are observed in the range of $2168 \mathrm{~cm}^{-1}$, for $\mathrm{C}=\mathrm{C}$ bond in the range of $1621 \mathrm{~cm}^{-1}$, for $\mathrm{C}-\mathrm{C}$ bond - in the range of $1650 \mathrm{~cm}^{-1}$, and for C-H bond - in the range of $3330 \mathrm{~cm}^{-1}$, which corresponds to the chemical structure of MIG-4E acetylene reagent.

Valence oscillations for $\mathrm{C} \equiv \mathrm{C}$ bond in DMIPEC reagent are observed in the range of $2260-2100 \mathrm{~cm}^{-1}$, for $\mathrm{C}=\mathrm{C}$ bonds - in the range of $1650 \mathrm{~cm}^{-1}$, and for $\mathrm{C}-\mathrm{C}$ bond in the region of $1650 \mathrm{~cm}^{-1}$, for $\mathrm{C}-\mathrm{H}$ bond - in the range of $3333-3267 \mathrm{~cm}^{-1}$, which corresponds to the chemical structure of molecules of DMIPEC acetylene reagent.

The IR spectroscopy results allow us to assume that chemical bonds are formed between the reagent molecules and surface of minerals because of the MIG-4E reagent adsorption on $\mathrm{PbS}$ minerals (Fig. 2, b). The formation of such bonds can be judged by changes in the frequency spectrum from $2168 \mathrm{~cm}^{-1}$ in the reagent, the intensity of which decreases during adsorption and shifts to a low side up to $2050 \mathrm{~cm}^{-1}$, being evidence of the $\pi$-bond formation between lead $(\mathrm{Pb})$ atoms and acetylene $\mathrm{p}$ - bond. By shifting the frequency spectrum from $1621 \mathrm{~cm}^{-1}$ to $1550 \mathrm{~cm}^{-1}$ and reducing their intensity, it can be assumed that $\pi$-bonds are formed between $\mathrm{Pb}$ atoms and the double alkene bond.

The results of IR spectroscopic analysis of DMIPEC reagent have shown that a chemical bond is likely to form when the reagent molecules are adsorbed on molybdenite $\left(\mathrm{Mo}_{2} \mathrm{~S}\right)$ surface $(\mathbf{F i g} . \mathbf{3}, \boldsymbol{b})$, as may be evidenced by a decrease in the intensity of the spectrum bands in the $2950 \mathrm{~cm}^{-1}$ frequency range, which corresponds to fluctuations in the $\mathrm{C}-\mathrm{H}$ bond of the reagent carbon skeletons.

In addition, $\gamma(\mathrm{C} \equiv \mathrm{C})$ absorption band in the IR spectra (Fig. 3, b) is shifted by $300 \mathrm{~cm}^{-1}$ into the low-frequency spectrum area from $2400 \mathrm{~cm}^{-1}$ to $2100 \mathrm{~cm}^{-1}$ during the adsorption of DMIPEC reagent molecules on the surface of molybdenite, which also indicates the formation of $\pi$-bonds between molybdenite atoms and acetylene 
bonds. For individual molecules of acetylene itself, the displacement band in the IR region, as a rule, does not appear at all because of the symmetry of the molecule. The band intensity is greatest only when $\mathrm{C} \equiv \mathrm{C}$ is located at the edge of the molecule, which is typical for terminal acetylene alcohols and decreases rapidly when it is moved to the middle. Just like in the case of MIG-4E reagent, the frequency spectrum has a decrease in intensity and a shift from $1600 \mathrm{~cm}^{-1}$ to $1450 \mathrm{~cm}^{-1}$ when DMIPEC reagent molecules are adsorbed on molybdenite $\left(\mathrm{Mo}_{2} \mathrm{~S}\right)$ surface, which shows the presence of $\pi$-bonds between Mo atoms and the double bond of DMIPEC reagent molecules. For terminal reagents with an terminal acetylene group, such as DC-80, DC-90 and DC-100, a narrow absorption band $\gamma(\mathrm{C}-\mathrm{C})$ is observed in the range of $3300 \mathrm{~cm}^{-1}$ [33-34].

In the coordination complex, the spectrum shift is a consequence of the electron density displacement from metal cations in the direction of an antibonding $\pi$-orbital of acetylene ligand, while the acetylene bond ceases to be linear. If the coordination bond in the acetylene complex is in the coordination plane, then acetylene hydrocarbons form trinomial cycles with metal atoms, typical for such transition metals in the zero oxidation state as $\mathrm{Ni}(0), \mathrm{Pd}(0)$ and $\mathrm{Pt}(0)$.

Acetylene reagents, despite the fact that the nucleophilic addition reaction is preferable for a triple acetylene bond, have the ability to enter into an electrophilic addition reaction as well. Besides, the structure of molecules may also contain double alkene bonds, for which the main reaction mechanism is electrophilic addition that provides such molecules with special properties manifesting themselves during the flotation of sulphide ores.

To understand the reason, why acetylene alcohols form $\pi$-complexes with metal cations by acetylene bond rather than covalent bonds due to the breaking of one of their acetylene p-bonds, it is necessary to take into account that the formation of a $\pi$-complex does not require the metal atom conversion to an excited state, and the reaction proceeds in compliance with the nucleophilic type, while, taking into account the data in Table $\mathbf{4}$, alcohol molecules need an additional energy of $\sim 230-163=67 \mathrm{kcal}$ to break one of the acetylene bonds.

For a more detailed representation of the processes occurring during the interaction of acetylene reagent molecules with the surface of sulphide minerals, the energy diagrams represent the difference in the reaction mechanisms of complex formation by nucleophilic and electrophilic mechanisms (Fig. 4). In compliance with the nucleophilic mechanism, valence electrons are delivered from orbitals of alkynes to unpaired orbitals of metal atoms; according to the electrophilic mechanism, electrons are delivered from valence orbitals of excited metal atoms to the free valence orbitals of alkenes [35].

The model of electronic formula of the $[\mathrm{Pb}] \mathrm{C}_{2} \mathrm{H}_{2}$ $\pi$-complex is shown in Fig. 5, $\boldsymbol{a}$. The model is constructed

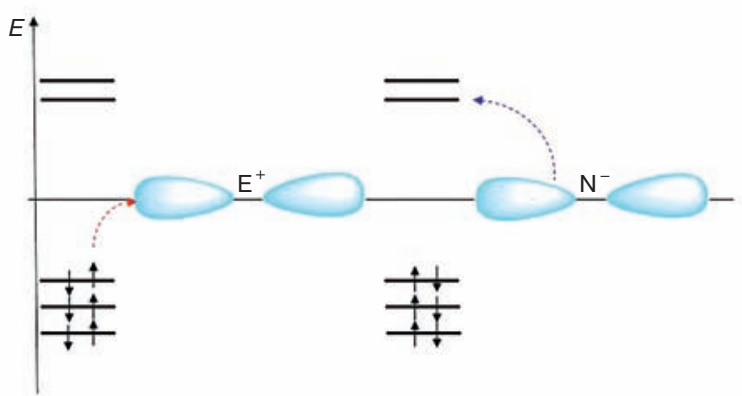

Fig. 4. Model of electrophilic and nucleophilic substitution in the MO method [31]
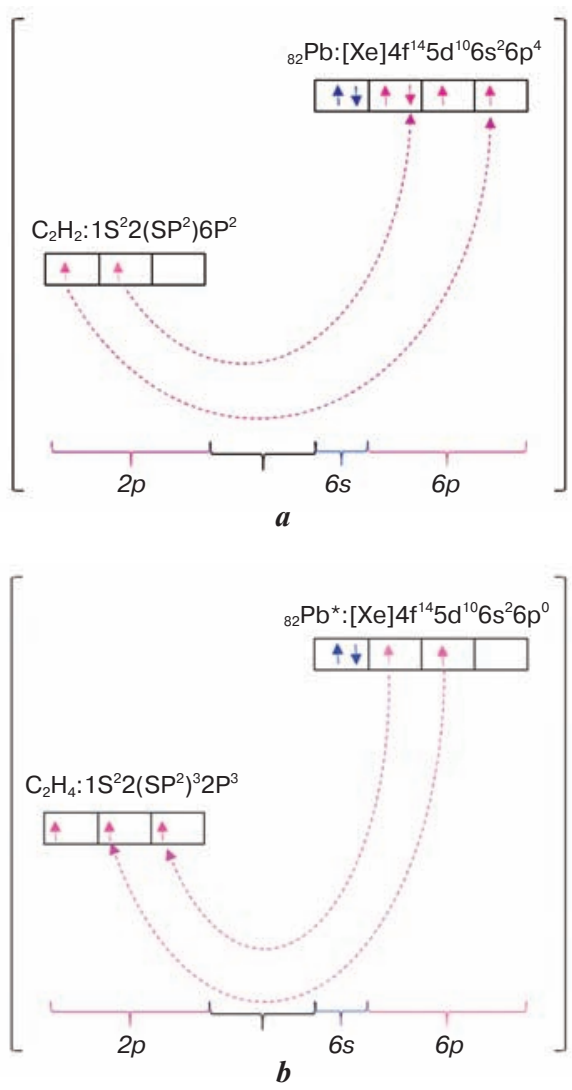

Fig. 5. Model of electronic formula of $\pi$-complexes: $a-[\mathrm{Pb}] \mathrm{C}_{2} \mathrm{H}_{2} ; b-[\mathrm{Pb}]^{*} \mathrm{C}_{2} \mathrm{H}_{4}$

taking into account the nucleophilic nature of substitution in the MO (molecular orbitals) method, when electrons are transferred from valence orbitals of the nucleophile $\left(\mathrm{C}_{2} \mathrm{H}_{2}\right)$ to the lowest free valence $\mathrm{MO}$ of $\mathrm{Pb}^{0}$ ligand in the ground state.

Fig. 5, $\boldsymbol{b}$ demonstrates the model of electronic formula of the $[\mathrm{Pb}]^{*} \mathrm{C}_{2} \mathrm{H}_{4} \pi$-complex. The model is constructed 
taking into account the electrophilic nature of substitution in the MO method, when electrons are displaced from valence orbitals of the excited $\mathrm{Pb}$ ligand to the lowest free valence $\mathrm{MO}$ of the electrophile $\left(\mathrm{C}_{2} \mathrm{H}_{4}\right)$, valence is $\mathrm{Pb}^{+2}$.

It is known from the chemistry of coordination compounds that when interacting with salts and transition metal complexes, acetylenes form a family of $\pi$-complexes, which are products of intermediate stages in chemical syntheses [36]. Similar information for transition metal sulphides and tertiary acetylene alcohols is lacking. That is why our investigations have been aimed at studying the
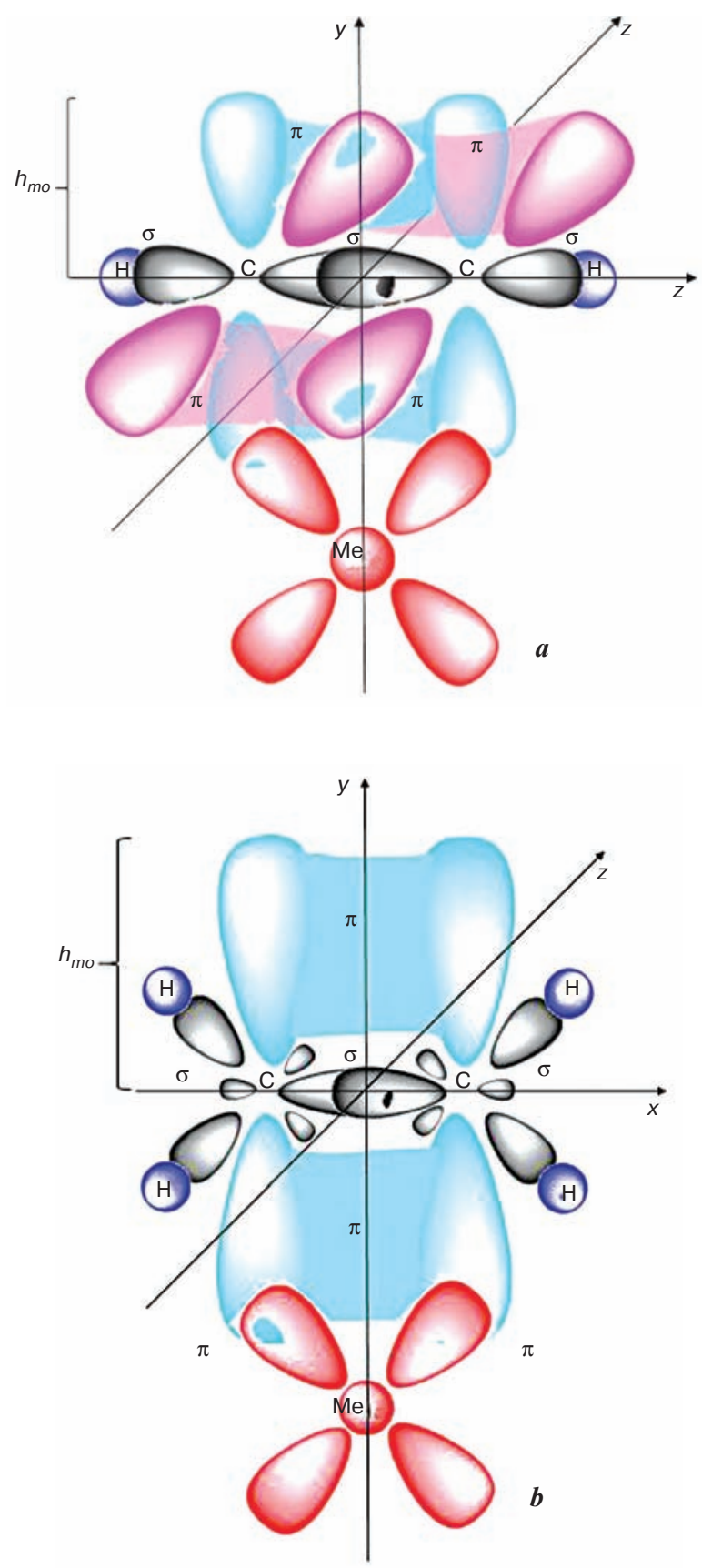

Fig. 6. Simplified models of the formation of $\pi$-complexes of alkynes with sulphide mineral atoms:

$a-\pi_{\mathrm{II}} \rightarrow d_{x y}$ type and alkenes; $b-\pi_{\mathrm{II}} \rightarrow d_{x y}$ type, where: $h_{o m}$ is the value corresponding to the molecular $p$-orbital radius interaction of acetylene reagent molecules with the surface of sulphide minerals of the transition group metals in the process of flotation.

The characteristic nucleophilic addition for alkynes is determined by a negatively charged particle having a free electron pair. During the formation of a $\pi$-complex between MeS and acetylene alcohol molecules, an acetylene bond is the electron pair donor (Fig. 6, a). The formation of a $\pi$-complex between $\mathrm{MeS}$ and alkene molecules (Fig. 6, b) proceeds through two parallel processes: 1 - displacement of electrons from the filled $p$-orbital of olefin to an unoccupied orbital of the metal atom (donoracceptor bond); 2 - inverse donor interaction of a filled metal atom orbital with an unoccupied $p$-orbital of olefin (dative bond). In this configuration, when the electron bunches overlap, the alkene electrons continue to remain on their orbitals.

The mutual overlap of electron bunches in the same plane allows electrons to move along the generalized orbital of the $\pi$-complexes formed.

The presented data make it is possible to formulate some differences in the formation of $\pi$-complexes between $\mathrm{MeS}$ and alkynes, MeS and alkenes, consisting in the fact that a lower (close to the core) arrangement of the $P$-orbitals of alkynes will provide greater stability of the complexes formed than that of the complexes formed by alkenes. Moreover, the existing differences in the magnitude of binding energy of the complexes in favor of alkynes $(\Delta+1.2 \mathrm{Ev})$ and an arrangement of molecular orbitals of alkenes provide high selectivity with respect to $\mathrm{MeS}$ cations of alkyne molecules, which is important for the extraction and separation of minerals In the course of flotation.

According to the Lewis theory (HSAB concept) and the Pearson principle [22-23], alkenes (Fig. 6, b) are weak bases; they do not form strong complexes with acceptor molecules and can form stable complexes, mainly with transition group metals having the configuration of $d^{10}$ orbitals.

Modeling and calculating the quantum-chemical parameters of the structures under consideration formed in the flotation process have been performed by the methods of molecular mechanics, semi-empirical quantumchemical and non-empirical quantum-chemical methods using the ChemBio3D 11.0 package included in the ChemBioOffice 2008 package (for Windows), developed by CambridgeSoft Corporation. The MM2 (Molecular Mechanics) technique was chosen as an intermediate step for preliminary optimization of the structure of complex organic compounds. The MM2 technique is designed for modeling and calculating organic molecules. It takes into account the potential fields formed by all the atoms of the calculated system, in comparison with other methods of molecular mechanics [37].

The $\mathrm{MIG}-4 \mathrm{E}$ reagent, when adsorbed on $\mathrm{PbS}$ mineral surface, can form $\pi$-complexes by two mechanisms: nucleophilic (Fig. 7, a) and electrophilic (Fig. 7, b).

Fig. 7, $\boldsymbol{a}$ and Fig. 7, $\boldsymbol{b}$ show the separate formation of a $(\mathrm{MIG}-4 \mathrm{E}+\mathrm{PbS}) \pi$-complexes, since the nucleophilic 
mechanism of the complex formation reaction does not require the excited state of $\mathrm{Pb}$ atom in $\mathrm{PbS}$; the transfer of electrons from valence orbitals of the acetylen bond (Fig. 7, a) occurs to unoccupied valence orbitals of the sulphide in the ground state. For the $\pi$-complex formation by an electrophilic mechanism (Fig. 7, b), when the sulphide metal atom is in an excited state, electrons are transferred from its valence orbitals to unoccupied orbitals of the reagent double bond; for this it is necessary that $\mathrm{Pb}$ atom in $\mathrm{PbS}$ is in an excited state, i.e. energy must be transferred to the mineral.

For this reason, the probability that the adsorption of MIG-4E reagent molecule on $\mathrm{PbS}$ surface will results in simultaneous realization of such two mechanisms of formation of $\pi$-complexes [28] is very small, since it is rather difficult to create conditions when the surface of one mineral will have both the ground and excited state. The variant of simultaneous formation of $\pi$-complexes is only possible in the boundary $\sim 10 \mathrm{~nm}$ zone between atoms in the ground and excited states.

The DMIPEC reagent, when adsorbed on the surface of molybdenite $\left(\mathrm{Mo}_{2} \mathrm{~S}\right)$, can also form $\pi$-complexes by nucleophilic (Fig. 8, a) and electrophilic (Fig. 8, b) mechanisms and by a mixed one (Fig. 8, $\boldsymbol{c}$ ).

Calculated data for the total potential energy of the complexes formed by MIG-4E molecules with PbS surface according to the model shown in (Fig. 7, a) and DMIPEC molecules with $\mathrm{Mo}_{2} \mathrm{~S}$ surface according to the model shown in (Fig. 8, a) are given in Table 5.

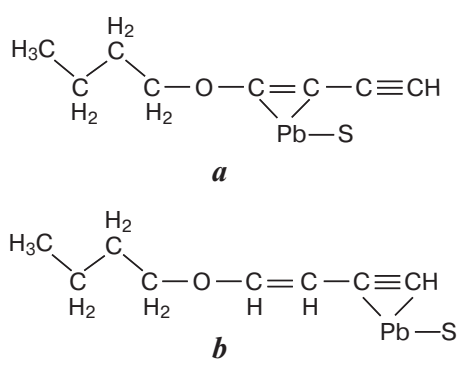

Fig. 7. Structure of $\pi$-complexes:

$a$ - calculated (MIG-4E $+\mathrm{PbS}) \pi$-complex- 1 by nucleophilic mechanism; $b$ - calculated (MIG-4E $+\mathrm{PbS}$ ) $\pi$-complex-2 by electrophilic mechanism<smiles>C=C(C)C1=C(C(C)(C)O)O1</smiles><smiles>CC(C)(O)C#CC(C)(C)O</smiles><smiles>CC(C)(O)C1=C(C(C)(C)O)C1[N+]([O-])([O-])O</smiles>

Fig. 8. Structure of $\pi$-complexes:

$a$-calculated (DMIPEC $+\mathrm{Mo}_{2} \mathrm{~S}$ ) $\pi$-complex-1 by nucleophilic mechanism; $b$-calculated (DMIPEC + Mo2S) $\pi$-complex- 2 by electrophilic mechanism; $c-$ calculated (DMIPEC $+\mathrm{Mo}_{2} \mathrm{~S}$ ) $\pi$-complex- 3 by mixed mechanism
Calculated data on the total potential energy of the complexes formed by MIG-4E molecules with PbS surface, according to the model shown in (Fig. 7, a), and DMIPEC molecules with $\mathrm{Mo}_{2} \mathrm{~S}$ surface according to the model shown in (Fig. 8, a), are given in Table 6. The total energy of $\pi$-complexes formed by the reagents by nucleophilic mechanism is close in value ( $8.2 \%$ difference) and amounts to $2514.0873 \mathrm{kcal} / \mathrm{mol}$ for the (MIG-4E $+\mathrm{PbS}$ ) complex, and $2306.1585 \mathrm{kcal} / \mathrm{mol}$ for the (DMIPEC + + Mo2S) complex in the (HUMO) state.-

Calculated data for the total potential energy of the complexes formed by MIG-4E molecules with PbS surface in compliance with the model shown in (Fig. 7, b), and DMIPEC molecules with $\mathrm{Mo}_{2} \mathrm{~S}$ surface in compliance with the model shown in (Fig. 8, b), are given in Table 6. The total energy of $\pi$-complexes formed by the reagents by electrophilic mechanism is $47.7 \%$ different from the reagent molecules and amounts to $270.0439 \mathrm{kcal} / \mathrm{mol}$ for (MIG-4E + PbS) complex, and $141.9386 \mathrm{kcal} / \mathrm{mol}$ for (DMIPEC $+\mathrm{Mo}_{2} \mathrm{~S}$ ) complex in the (HUMO) state. Such a difference in the total energy values of the complexes can be attributed to the presence of conformational ability in DMIPEC reagent molecules.

Table 5

Calculated data for the total potential energy

of the complexes formed by MIG-4E + PbS

and DMIPEC $+\mathrm{Mo}_{2} \mathrm{~S}$ molecules in the (HUMO) state by nucleophilic mechanism

\begin{tabular}{|l|c|c|}
\hline \multirow{2}{*}{ Calculated parameters } & MIG-4E + PbS & DMIPEC $+\mathrm{Mo}_{2} \mathrm{~S}$ \\
\cline { 2 - 3 } & \multicolumn{2}{|c|}{ Parameter value } \\
\hline Stretch & 109.6827 & 206.1713 \\
\hline Bend & 2423.5430 & 2129.1327 \\
\hline Stretch-Bend & -25.8660 & -27.9966 \\
\hline Torsion & 2.5841 & -0.1665 \\
\hline Non-1.4 VDW & -1.7454 & -6.0130 \\
\hline 1.4 VDW & 5.8889 & 5.0193 \\
\hline *Dipole/Dipole & 0.0000 & 0.0114 \\
\hline Total energy, kcal/mol & 2514.0873 & 2306.1585 \\
\hline \multirow{2}{*}{$\begin{array}{l}\text { *Contribution indicator of the Dipole/Dipole interaction } \\
\text { of molecules having dipole moments, adopted in the } \\
\text { calculations of the MM2 technique [37]. }\end{array}$}
\end{tabular}

Table 6

Calculated data for the total potential energy of MIG-4E + PbS and DMIPEC $+\mathrm{Mo}_{2} \mathrm{~S}$ complexes in the (HUMO) state by electrophilic mechanism

\begin{tabular}{|l|c|c|}
\hline \multirow{2}{*}{ Calculated parameters } & MIG-4E + PbS & \multicolumn{1}{|c|}{ DMIPEC $+\mathrm{Mo}_{2} \mathrm{~S}$} \\
\cline { 2 - 3 } & \multicolumn{2}{|c|}{ Parameter value } \\
\hline Stretch & 24.4271 & 6.8174 \\
\hline Bend & 247.1455 & 105.6229 \\
\hline Stretch-Bend & -3.4928 & -7.1160 \\
\hline Torsion & 0.0087 & 30.5413 \\
\hline Non-1.4 VDW & -1.7477 & -1.2661 \\
\hline 1.4 VDW & 3.7030 & 7.1724 \\
\hline Dipole/Dipole & 0.0000 & 0.1666 \\
\hline Total energy, kcal/mol & 270.0439 & 141.9386 \\
\hline
\end{tabular}


Table 7

Calculated data for the total potential energy of the complex formed by DMIPEC $+\mathrm{Mo}_{2} \mathrm{~S}$ molecule in the (HUMO) state by a mixed mechanism

\begin{tabular}{|l|c|}
\hline \multirow{2}{*}{ Calculated parameters } & DMIPEC $+\mathrm{MO}_{2} \mathrm{~S}$ \\
\cline { 2 - 2 } & Parameter value \\
\hline Stretch & 213.4535 \\
\hline Bend & 2236.9993 \\
\hline Stretch-Bend & -37.0622 \\
\hline Torsion & 30.6214 \\
\hline Non-1.4 VDW & -1.2295 \\
\hline 1.4 VDW & 10.2899 \\
\hline Dipole/Dipole & 0.0691 \\
\hline Total energy, kcal/mol & 2453.1415 \\
\hline
\end{tabular}<smiles>CC(C)(O)C#C[PH2+]C#CC(C)(C)O</smiles><smiles>CC(C)(O)C1=C[Pb]1</smiles>

Fig. 9. Calculated (DC- $80+\mathrm{PbS})$ complex by nucleophilic mechanism

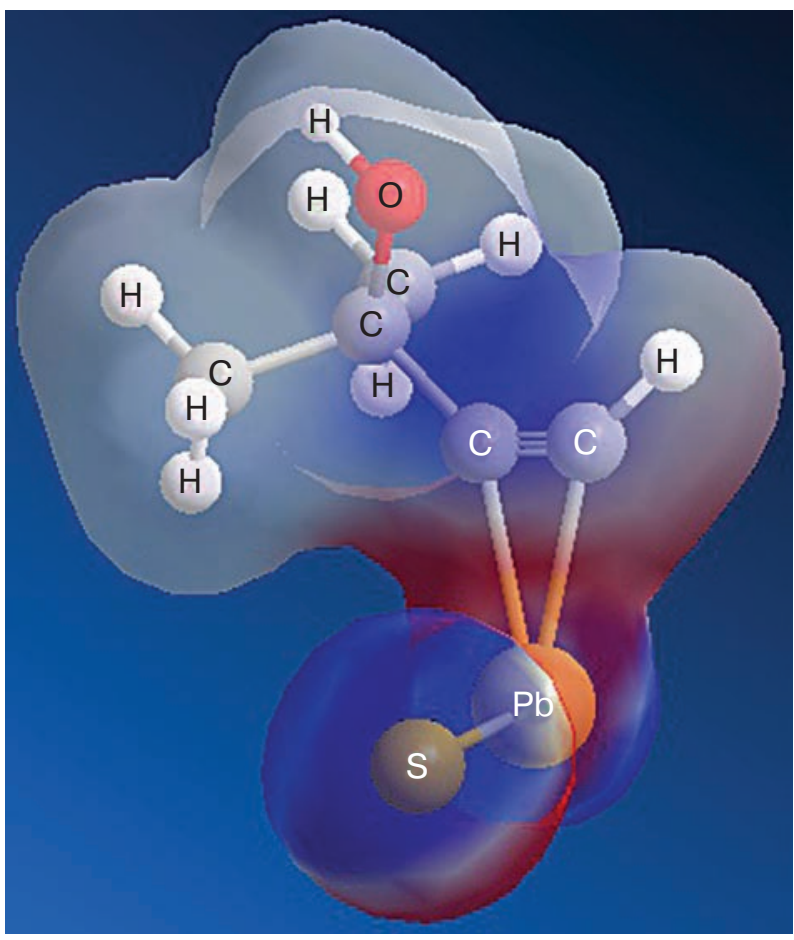

Fig. 10. 3D model of (DC- $80+\mathrm{PbS})(\mathrm{HUMO})$ complex by nucleophilic mechanism
Calculated data for the total potential energy of the complex formed by (DMIPEC $+\mathrm{Mo}_{2} \mathrm{~S}$ ) molecule in the (HUMO) state by a mixed mechanism are given in Table 7.

The total energy of the $\pi$-complex formed by DMIPEC reagent with molibdenite metal cation by a mixed mechanism is $2453.1415 \mathrm{kcal} / \mathrm{mol}$ in the (HUMO) state. Such a value of the total energy of the formed complex can also be connected with the presence of conformational ability in the DMIPEC reagent molecules.

For tertiary terminal acetylene alcohol, which is represented by DC-80 reagent (Fig. 1, c), two mechanisms of forming the complexes with sulphide cations are characteristic, the $\pi$-complex formed in compliance with the nucleophilic mechanism is shown in (Fig. 9) and the complex by substitution reaction of terminal hydrogen of $\mathrm{DC}-80$ reagent for $\mathrm{Pb}$ atom of a sulphide is shown in the reaction below:

$$
\mathrm{C}_{3} \mathrm{H}_{7} \mathrm{OC} \equiv \mathrm{CH}+\mathrm{PbSO}_{4} \rightarrow \mathrm{C}_{3} \mathrm{H}_{7} \mathrm{OC} \equiv \mathrm{C}-\mathrm{Pb}+\mathrm{SO}_{4}^{2-} \text {. }
$$

Fig. 10 demonstrates a 3D model of (DC-80 $+\mathrm{PbS})$ (HUMO) $\pi$-complex formed by nucleophilic mechanism.

Calculated data for the total potential energy of the complex-1 formed by DC-80 + PbS (HUMO) molecule by nucleophilic mechanism are given in Table 8 .

The reaction between alkyne- 1 molecules with terminal triple bond and transition metal salts proceeds with maintaining the triple bond in the resulting complex. Such an ability of alkynes-1 to replace a proton with a metal atom, like acids, is due to the fact that the carbon atom is in a state of $s p$-hybridization. As a result, the carbon atom

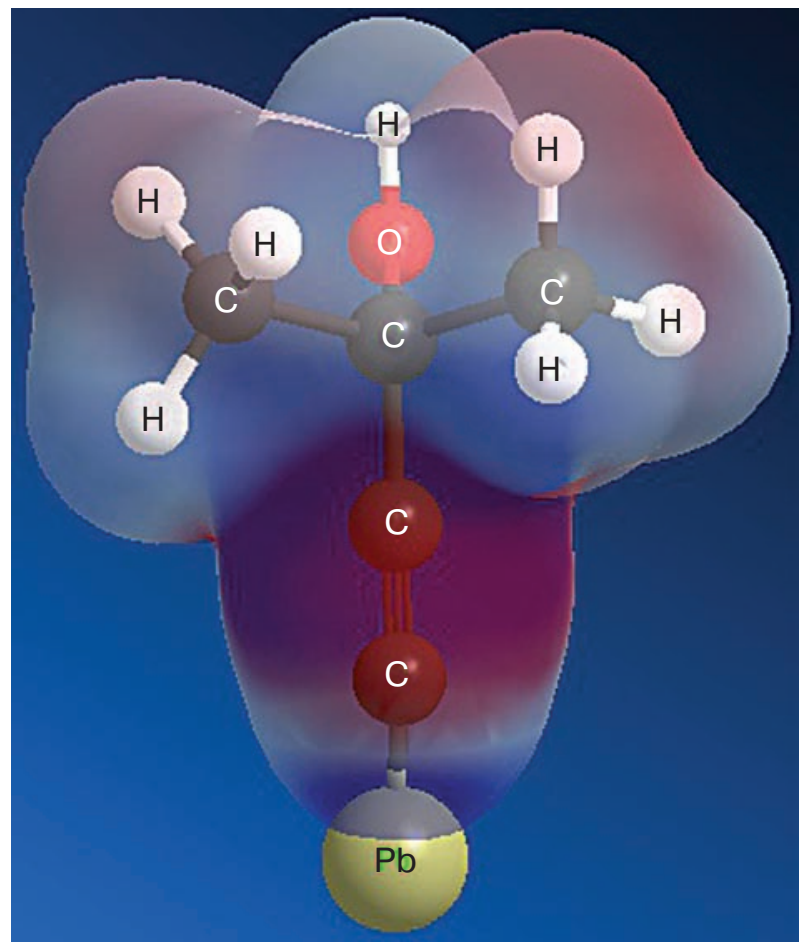

Fig. 11. $3 \mathrm{D}$ model of (DC-80 $+\mathrm{Pb})(\mathrm{HUMO})$ complex by substitution reaction 
Table 8

\begin{tabular}{l}
$\begin{array}{l}\text { Calculated data for the total potential energy of the } \\
\text { complex-1 formed by a DC-80 - PbS (HUMO) molecule } \\
\text { by nucleophilic mechanism }\end{array}$ \\
\hline \multicolumn{1}{|c|}{ Calculated parameters } \\
\hline Stretch
\end{tabular}

Table 9

Calculated data for the total potential energy of the complex formed by a DC-80 - Pb (HUMO) molecule by substitution reaction

\begin{tabular}{|l|c|}
\hline \multicolumn{1}{|c|}{ Calculated parameters } & Parameter value \\
\hline Stretch & 0.1763 \\
\hline Bend & 0.5725 \\
\hline Stretch-Bend & 0.0573 \\
\hline Torsion & 1.1962 \\
\hline Non-1.4 VDW & -1.3990 \\
\hline 1.4 VDW & -1.3990 \\
\hline Dipole/Dipole & 1.0193 \\
\hline Total energy, kcal/mol & 3.8989 \\
\hline
\end{tabular}

is more enriched with electron density and the proton becomes mobile. Alkynes, which do not have hydrogen atoms in a triple bond, do not enter into such a reaction, which makes it possible to distinguish them from each other.

In a reaction of the DC- 80 reagent proton substitution with $\mathrm{Pb}$ metal atom, the corresponding salts are formed in DC-80 reagent molecule when $\mathrm{PbSO}_{4}$ interacts with terminal carbon atom of the triple bond.

Fig. 11 shows a 3D model of a (DC-80 + Pb) (HUMO) $\pi$-complex formed by substitution reaction.

Table 9 contains calculated data for the total potential energy of the complex formed by a $(\mathrm{DC}-80+\mathrm{Pb}) \mathrm{mo}-$ lecule in the (HUMO) state by substitution reaction.

As a result of this interaction, a covalent bond "carbon-metal cation" is formed; however, the resulting compounds are not metal acetylenides, but are closer in properties to complex compounds.

\section{Conclusions}

Analysis of known data and results of the fulfilled flotation, adsorption, spectral IR studies and quantum-chemical calculations of various interaction mechanisms of acetylene reagents (MIG-4E, DMIPEC and DC-80) with galena $(\mathrm{PbS})$ and molybdenite $\left(\mathrm{Mo}_{2} \mathrm{~S}\right)$ sulphide minerals allowed us to draw the following conclusions. The IR spectroscopic investigations have shown that chemical bonds are formed as a result of adsorption of MIG-4E reagent molecules on galena $(\mathrm{PbS})$; chemical bonds are also formed during adsorption of DMIPEC reagent molecules on the surface of molybdenite $\left(\mathrm{Mo}_{2} \mathrm{~S}\right)$, the presence of which is established by reducing the intensity of the spectrum bands in the frequency range of $2950 \mathrm{~cm}^{-1}$, which corresponds to fluctuations in the $\mathrm{C}-\mathrm{H}$ bond of the carbon skeleton of reagents.

Quantum-chemical calculations of the complex-1 total potential energy have shown that the (HUMO) complex formed by a MIG-4E molecule with the galena $(\mathrm{PbS})$ metal cation by nucleophilic mechanism is 2514.0873 $\mathrm{kcal} / \mathrm{mol}$, which is almost an order of magnitude greater than that of complex-2, formed by a MIG-4E - PbS complex molecule (HUMO) by electrophilic mechanism, which is $270.0439 \mathrm{kcal} / \mathrm{mol}$. Analysis of calculated data on the total potential energy of complexes formed by MIG-4E molecules with PbS surface and DMIPEC molecules with $\mathrm{Mo}_{2} \mathrm{~S}$ surface has showed that the total energy of $\pi$-complexes formed by the reagents by electrophilic mechanism differs by $47.7 \%$ for reagent molecules and is $270.0439 \mathrm{kcal} / \mathrm{mol}$ for (MIG-4E + PbS) complex, and $141.9386 \mathrm{kcal} / \mathrm{mol}$ for (DMIPEC $+\mathrm{Mo}_{2} \mathrm{~S}$ ) complex in the (HUMO) state. Such a difference in the total energy values of the complexes can be attributed to the presence of conformational ability in DMIPEC molecules.

The calculations of the simplest quantum-chemical parameters of the complexes make it possible to more fully evaluate the influence of the bond structure in the hydrocarbon chain of reagents and transition metal atoms on reactivity, to determine the reason of the orienting influence of the arrangement of bonds in the reagent molecule.

The use of DMIPEK and DC-80 acetylene alcohols as selective additional collectors interacting with the surface of sulphide minerals mainly by nucleophilic mechanism during flotation of a number of ores of non-ferrous and noble metals leads to an increase in the floatability of sulphide minerals and, as a consequence, to an increase in the extraction of target metals, by $3-10 \%$ on average, which makes it possible to consider the reagents based on acetylene derivatives as promising for industrial applications.

\section{References}

1. Abramov A. A. Theory of Creation of Innovation Flotation Technologies. Part 1. Theory of Modern Flotation. Tsvetnye Metally. 2013. No. 2. pp. 41-45.

2. Taggart A. F., del Guidice G. R. M., Ziehl O. A. The Case for the Chemical Theory of Flotation. American Institute of Mining, Metallurgical and Petroleum Engineers. Transactions. 1934. Vol. 112. pp. 348-381.

3. Shvedov D. A. Hypothesis for the Causes of Easy Floatability of Sulphde Minerals and Difficult Floatability of Oxidized Minerals. Journal of Mining Institute. 1937. Vol. X, Iss. 3. pp. 71-77.

4. Shvedov D. A., Shorsher I. N. The Oxidation Effect on the Flotation of Sulphide Minerals. Collection of Research Papers 
on the Theory and Practice of Flotation. Leningrad: Institut "Mekhanobr", 1938. pp. 5-27.

5. Klassen V. I., Mokrousov V. A. Introduction to Flotation Theory. Moscow: Metallugizdat, 1953. 463 p.

6. Plaksin I. N., Shafeev R. Sh. On the Effect of Electrochemical Potential on Xanthate Distribution on Sulfide Surface. Doklady Akademii Nauk SSSR. 1958. Vol. 118, No. 3. pp. 546-548.

7. Plaksin I. N., Shafeev R. Sh. On Quantitative Evaluation of Xanthate Attachment in Terms of Surface Properties of Sulphide Minerals. Doklady Akademii Nauk SSSR. 1959. Vol. 128, No. 4. pp. 777-780.

8. Lippinen J. O., Basilio C. I., Yoon R.-H. In-situ FTIR Study of Ethyl Xanthate Adsorption on Sulfide Minerals Under Conditions of Controlled Potential. International Journal of Mineral Processing. 1989. Vol. 26. pp. 259-274.

9. Finkelstein N. P., Poling G. W. The Role of Dithiolates in Flotation of Sulfide Minerals. Mineral Science Engineering. 1977. Vol. 9. pp. 177-197.

10. Kondratiev S. A., Moshkin N. P., Konovalov I. A. Evaluation of Collecting Ability of Xanthate Forms Easily Desorbed from Mineral Surface. Journal of Mining Science. 2015. No. 4. pp. 164-173.

11. Bulatovic Srdjan M. Handbook of Flotation Reagents. Chemistry, Theory and Practice. Flotation of Sulfide Ores. Elsevier Science \& Technology Books, 2007. 446 p.

12. Finkelstein N. P., Allison S. A. Natural and Induced Hydrophobicity in Sulphide Mineral Systems. Aiclhe Symposium Series. 1976. Vol. 71, Iss. 150. P. 165-175.

13. Abramov A. A. Theory of Creation of Innovation Flotation Technologies. Part III. Theory of Intensification of Technological Processes of Flotation. Tsvetnye Metally. 2013. No. 4. pp. 12-17.

14. Bogdanov O. S., Maksimov I. I., Podnek A. K., Yanis N. A. Theory and Technology of Ore Flotation. Moscow: Nedra, 1990. $363 \mathrm{p}$.

15. Shubov L. Ya., Ivankov S. I., Shcheglova I. K. Flotation Reagents in the Processes of Mineral Raw Material Enrichment. Handbook. Moscow : Nedra, 1990. In 2 books. Book 1. 400 p.

16. Abramov A. A. Flotation: Collecting Reagents. Collection of Research Works. Vol. 7. Moscow : Gornaya Kniga, 2012. 656 p.

17. Kurkov A. V., Pastukhova I. V. Development of Effective Flotation Reagents Based on New Types of Raw Materials and Production Waste. Modern Problems of Complex Processing of Natural and Technogenic Mineral Raw Materials : Collection of Works. St. Petersburg, 2005. pp. 17-23.

18. Abramov A. A. Theory of Creation of Innovation Flotation Technologies. Part IV. Theory of Increasing of Selectivity of the Collectors Operation During the Process of Flotation. Tsvetnye Metally. 2013. No. 5. pp. 12-18.

19. Glembotsky A. V., Podvishensky N. S., Ivankov S. I. Mechanism of Chemisorption of MIG-4E Reagent on Minerals of Sulphide Ores. Tsvetnye Metally. 1986. No. 10. pp. 87-90.

20. Shchelkunov S. A., Malyshev O. A. Foaming Agent for Flotation of Minerals. Eurasian Patent, No. 027616. Published: 31.08.17.

21. Shchelkunov S. A., Malyshev O. A., Yushina T. I., Dunaeva V. N. Flotation Properties of Additional Collectors, Foaming Agents Based on Acetylenic Alcohols. Non-ferrous Metals. 2015. No. 2. pp. 3-10. DOI: 10.17580/nfm.2015.02.01.
22. Pearson R. J. Hard and Soft Acids and Bases. Uspekhi khimii. 1971. Vol. 40, Iss. 7. pp.1259-1282.

23. March J. Advanced Organic Chemistry. Reactions, Mechanisms, and Structure. In 4 vols. Vol. 1. Translated from English. Moscow : Mir, 1987. 381 p.

24. Yushina T. I., Malyshev O. A., Shshelkunov S. A., Khrustalev D. P. Peculiarities of The DC-80 Reagent Based on Acethylenic Alcohols Effect in Flotation Processes. Non-ferrous Metals. 2016. No. 2. pp. 7-11. DOI: 10.17580/nfm.2016.02.02.

25. Yushina T. I., Purev B., D’Elia Yanes K. S., Malofeeva P. R. Improvement of Porphyry Copper Flotation Efficiency with Auxiliary Collecting Agents Based on Acetylene Alcohols. Eurasian Mining. 2019. No. 1. pp. 25-30. DOI: 10.17580/ em.2019.01.06.

26. Yushina T. I., Purev B., D’Elia K., Namuungerel B. Analysis of Technological Schemes and Substantiation of the Selection of the Reagent Regimes for Copper-Molybdenum Ores Flotation. Non-ferrous Metals. 2019. No. 1. pp. 3-11. DOI: 10.17580/nfm.2019.01.01.

27. Yushina T. I., Purev B., Namuungerel B. Substantiation of the Erdenetiyn-Ovoo Copper-Molybdenum Ore Flotation Technology with the Use of Tertiary Acetylene Alcohols. Non-ferrous Metals. 2020. No. 2. pp. 3-10. DOI: 10.17580/ nfm.2020.02.01.

28. Ivanova N. M., Shchelkunov C. A., Malyshev O. A. Quantum-Chemical Study of the Reaction of penta-4-en-2-yn1-ol with Copper, Zinc, and Nickel Sulfides. Russian Journal of General Chemistry. 2007. Vol. 77, Iss. 7. pp. 1263-1267.

29. Cotton F. A., Wilkinson G. Advanced Inorganic Chemistry. Part 1. Transl. from Eng. by Churanov S. S. Moscow: Izdatelstvo "Mir", 1969. 224 p.

30. Nakamoto K. Infrared and Raman Spectra of Inorganic and Coordination Compounds. Transl. from Eng. by Khristenko L. V. Moscow: Izdatelstvo Mir, 1991. 536 p.

31. Tarasevich B. N. IR Spectra of the Main classes of Organic Compounds. Moscow: Izdatelstvo MGU im. M. V. Lomonosova, 2012. 55 p.

32. Ivankov S. N. Separation of Mineral Complexes of TinPolymetallic Ores And Technogenic Formations of Noble and Non-Ferrous Metals on the Basis of Directed Changes in the Physicochemical State of the Surface of Minerals: Thesis of Inauguration of Dissertation ... of Doctor of Technical Sciences. Moscow, 1997. $62 \mathrm{p}$.

33. Kukushkin Yu. N. Chemistry of Coordination Compounds. Moscow : Vysshaya Shkola, 1985. 455 p.

34. Kazitsyna L. A., Kupletskaya N. B. Application of UV, IR, NMR and Mass Spectroscopy in Organic Chemistry. Moscow : Izdatelstvo MGU, 1979. 240 p.

35. Minkin V. I., Simkin B. Ya., Minyaev R.M. Theory of Molecule Structure. Rostov-on-Don : Fenix, 1997. 560 p.

36. Shteingarts V. D. Coordination Catalysis In The Chemistry Of Unsaturated Compounds. Soros Educational Journal. 1996. No. 7. pp. 47-58.

37. Chem \& BioOffice Desktop 2008 for Windows. User's Guide. CambridgeSoft, 2008. 579 p.

38. Khan G. A., Gabrielova L. I., Vlasova N. S. Flotation reagents and their use. Moscow : Nedra, 1986. 270 p. 